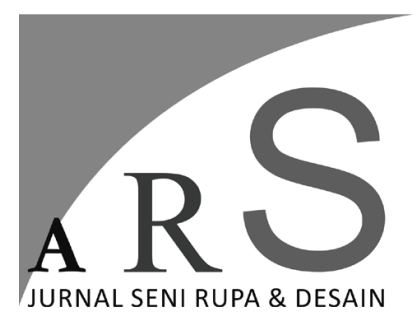

Volume 23 Nomor 2 Mei - Agustus 2020

\section{PENCAPAIAN MEDIA DIGITAL DALAM PENANAMAN KARAKTER PROGAM STUDI UNGGULAN (STUDI KASUS PROGRAM STUDI DESAIN KOMUNIKASI VISUAL UNIVERSITAS DIAN NUSWANTORO)}

\author{
Agus Setiawan, Ahmad Akrom \\ Program Studi Desain Komunikasi Visual, Fakultas Ilmu Komputer \\ Universitas Dian Nuswantoro \\ Jl. Imam Bonjol No 207 Semarang \\ E-mail: agus.setiawan@dsn.dinus.ac.id
}

\begin{abstract}
ABSTRAK
Pencapaian Media Digital Dalam Penanaman Karakter Progam Studi Unggulan (Studi Kasus Program Studi Desain Komunikasi Visual Universitas Dian Nuswantoro). Dalam penelitian dirumuskan bagaimana pencapaian media digital dalam upaya menanamkan karakter prodi unggulan pada mahasiswa. Adapun tujuan penelitian adalah mengetahui dan memahami media digital dalam upaya menanamkan karakter prodi unggulan pada mahasiswa Program Studi Desain Komunikasi Visual Universitas Dian Nuswantoro Metode penelitian menggunakan metode kualitatif yang lebih ditekankan pada observasi, wawancara, dokumentasi. Peneliti sebagai partisipan untuk menangkap aspek yang diteliti dan target luaran yang dicapai yaitu media digital berupa video profil program studi. Luaran penelitian ini meliputi Jurnal Nasional Terakreditasi terindeks Sinta 4, ARS: Jurnal Seni Rupa dan Desain, Institut Seni Indonesia Yogyakarta, Pemakalah dan artikel ilmiah dimuat dalam Prosiding Seminar Nasional Pascasarjana UNS 2020 Universitas Sebelas Maret, dan Bahan Ajar materi perkuliahan pada mata kuliah Pengantar Desain Komunikasi Visual.
\end{abstract}

Kata kunci: media digital, karakter, unggulan

\begin{abstract}
The Achievement Of Digital Media In Planting Program Characters Of Superior Studies (Case Study Of Visual Communication Design Communication Study Program Dian Nuswantoro) Achievement of Digital Media in Cultivating the Character of a Competitive Study Program (Case Study of Visual Communication Design Study Program at Dian Nuswantoro University). In the research, it was formulated how the achievement of digital media to instill excellent study program characters in students. The research objective is to know and understand digital media to instill excellent study program characters in students of the Visual Communication Design Study Program at Dian Nuswantoro University The research method uses qualitative methods which are more emphasized on observation, interviews, documentation. Researchers as participants to capture the aspects studied and target outcomes achieved are digital media in the form of study program profile videos. The outputs of this research include the Sinta 4 indexed accredited national journals, namely the ARS journal: Journal of Fine Arts and Design, Yogyakarta Indonesian Art Institute, Speakers and scientific articles published in the proceedings of the national seminar UNS 2020 Postgraduate Seminar, Sebelas Maret University, and Teaching Materials lecture material in the eyes Lecture Introduction to Visual Communication Design.
\end{abstract}

Keywords: digital media, character, featured 


\section{Pendahuluan}

Progam studi unggulan menjadi cerminan kualitas pendidikan bermutu dari sisi input dan output perguruan tinggi. Program studi berupaya semaksimal mungkin untuk mencapai sebuah kualitas yang benar-benar diperuntukkan kepada mahasiswa dan masyarakat luas, agar tercapainya cita-cita sumber daya manusia yang unggul pada tataran masyarakat yang santun dan bermartabat. Tercapainya sebuah prestasi yang unggul harus tercerminkan dalam model-model proses pembelajaran bermutu, sarana prasanana memadai, SDM bermutu dan produktif, dan yang tidak kalah pentingnya adalah pemberian kenyamanan kepada mahasiswa dalam hal motivasi belajar. Metode-metode perlu dikembangkan guna mencapai penanaman karakter program studi unggulan dengan kualitas pemahaman dan pemaknaan kompetensi keilmuan yang sudah menjadi pilihan.

Pepatah tak kenal maka tak sayang menjadi sumber inspirasi dalam penanaman karakter program studi unggulan melalui pencapaian media digital. Dalam upaya mengenalkan lebih jauh tentang program studi ungulan maka perlu media yang sekiranya mampu mengenalkan sebagian kompetensi unggulan program studi dalam kasus ini adalah program studi desain komunikasi visual, sehingga mahasiswa mampu memahami dan sudah mantap pada pilihannya. Pencapaian media digital perlu diupayakan sebagai langkah awal mengenalkan wajah sebuah program studi desain komunikasi visual sebagai prodi unggulan. Program studi unggulan yang dimaksudkan adalah program studi dengan capaian akreditasi A.

Keberadaan media digital dapat digunakan sebagai media pengenalan, pembelajaran kepada mahasiswa dan calon mahasiswa baru serta masyarakat, bahwa pilihannya sudah tepat dan berada pada tempat yang tepat pula. Keberadaan media digital dalam bentuk video profil prodi desain komunikasi visual jika dilihat dimedia maya sudah banyak sebagai contoh profil Desain Komunikasi Visual Universitas Telkom, profil Desain Komunikasi Visual Institut Seni Indonesia Yogyakarta, Profil Desain Komunikasi Visual Universitas Negeri Malang, profil Desain Komunikasi Visual UPI, dan profil Desain Komunikasi Binus University dan masih banyak lagi. Berdasarkan dari hal tersebut berarti terjadi persaingan dalam menanamkan karakter program studi unggulan melalui media pencapaian media digital yaitu media web, youtube, Instagram dan facebook.

Hasil pengamatan selama ini program studi Desain Komunikasi Visual Universitas Dian Nuswantoro sebagai program studi unggulan belum memiliki media digital berupa video profil program studi, yang ada hanya kegiatan-kegiatan pameran tugas akhir mahasiswa dengan inisiatif sendiri oleh mahasiswa dalam mengabadikan peristiwa yang mereka alami dengan menciptakan media video kegiatan. Pencapaian media digital berupa kegiatan mahasiswa yang tersajikan melalui media web, youtube, Instagram dan facebok diupayakan untuk penanaman karakter program studi unggulan kepada mahasiswa. Pencapaian media digital setidaknya terkonsep dalam literasi digital.

Martin berpendapat, bahwa literasi digital adalah kesadaran, sikap dan kemampuan individu untuk menggunakan alat dan fasilitas digital secara tepat untuk mengidentifikasi, mengakses, mengelola, mengintegrasikan, mengevaluasi, menganalisis, dan mensintesis. sumber daya digital, membangun pengetahuan baru, membuat ekspresi media, dan berkomunikasi dengan yang lain, dalam konteks situasi kehidupan tertentu, untuk memungkinkan tindakan sosial yang konstruktif; dan untuk merefleksikan proses ini (Koltay, 2011:216). Berdasarkan pengertian di atas dapat dibawa ke arah pencapaian media digital yaitu tindakan untuk mengakses, menidentifikasi, menganalisis dan membangun pengetahuan baru melalui media digital berupa web, youtube, Instagram, dan facebook. Melalui media tersebut diharapkan tercipta pembentukan wajah program studi unggulan mampu memberikan ruang interaksi kearah pemahaman dan pemantapan pilihan.

Solusi yang dicapai adalah tercapainya media digital sebagai penanaman karater tentang wajah sebuah program studi yang unggul sehingga secara konsep literasi media memicu pengetahuan baru tentang sebuah progam studi yang unggul. Di sisi lain, pencapaian media digital menjadi langkah lanjutan dari penelitian yang pernah dilakukan terkait pengembangan institusi pada program studi Desain Komunikasi Visual Udinus yaitu penciptaan web DKV Udinus sebagai bentuk wadah literasi visual dan tata kelola pameran yang mengarah pada konsep pameran digital. Untuk melengkapi dari dari keberadaan program studi dalam katagori A maka 
perlu terciptanya video profil prodi dalam menjawab tantangan sebagai program studi unggulan.

\section{Metode Penelitian}

Penelitian dengan metode kualitatif menekankan pada observasi dan wawancara dicapai dalam menjelaskan permasalahan. Metode kualitatif merupakan proses penelitian dan pemahaman dengan melibatkan diri yang berdasarkan pada metode yang menyelidiki suatu fenomena sosial dan masalah manusia. Pendekatan akan menghasilkan suatu gambaran permasalahan dengan meneliti katakata, laporan terinci dari pandangan informan atau narasumber, dan melakukan studi pada situasi yang alami (Creswell 1998, 2016) Penelitian ini akan menghasilkan data deskriptif permasalahan yang diangkat.

Sehingga dapat dilihat secara garis besar bagan penelitian secara utuh dalam pentahapannya dalam tabel di bawah ini:

Tabel 1 alur aspek yang diteliti dan target luaran yang dicapai

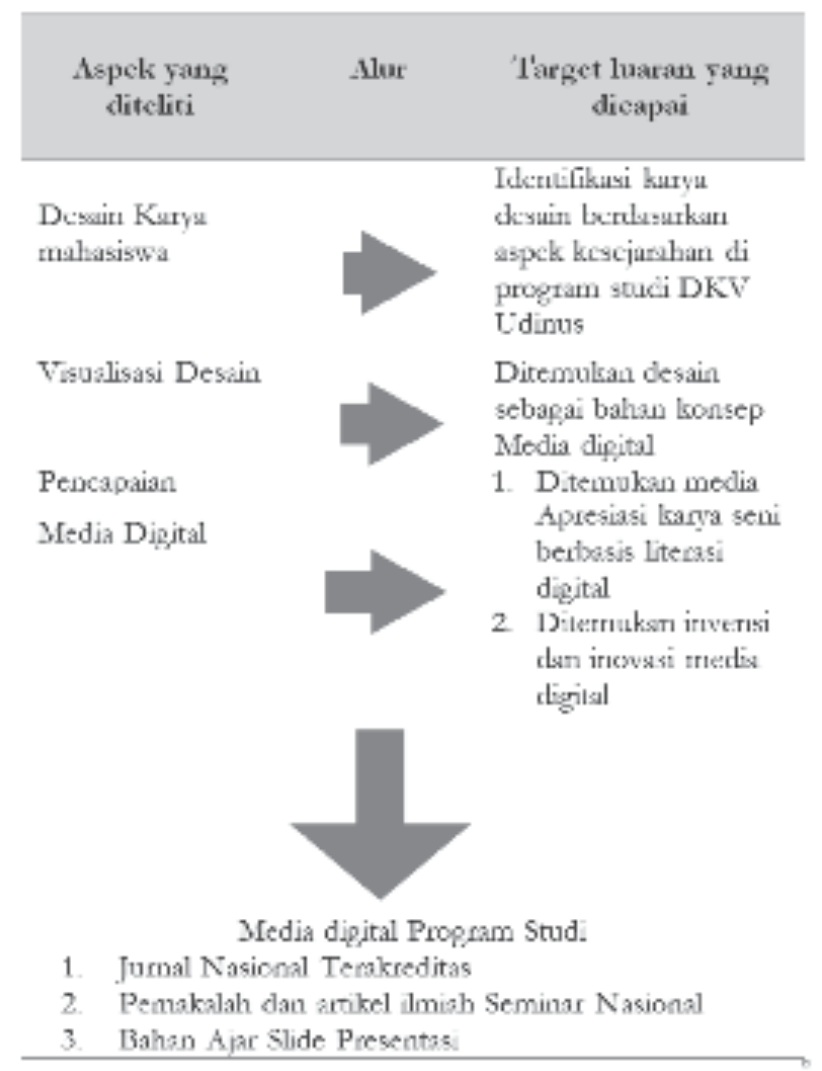

\section{Hasil dan Pembahasan}

\section{Program Studi Desain Komunikasi Visual Udinus}

Program Sudi DKV mendapatkan ijin penyelenggaraan program studi dari DIKTI melalui surat keputusan Nomor: 4067/D/T/2006 tanggal 6 November 2006. Program Studi Desain Komunikasi Visual Udinus telah berkembang sejak tahun 2007 sampai sekarang dengan perkembangan yang semakin baik dari tahun ke tahun, dan pada tahun 2015 mendapatkan nilai akreditasi A dari BAN-PT dengan surat keputusan Nomor 1151/SK/BAN-PT/Akred/S/ XI/2015 tanggal 14 November 2015 (Nugraini 2019:1). Adapun visi dan misi program Studi Desain Komunikasi Visual sebagai berikut;

Visi

"Menjadi Program Studi pilihan utama dalam bidang Desain Komunikasi Visual dan teknologi multimedia di Indonesia, yang unggul dan berjiwa entrepreneurship pada tahun 2021".

Misi

1. Menyelenggarakan pendidikan tinggi yang berbasis seni dan teknologi informasi untuk menghasilkan lulusan yang unggul dan mampu mengembangkan serta mengamalkan ilmunya secara profesional.

2. Menjaga keterkaitan dan relevansi seluruh kegiatan akademis dengan kebutuhan pembangunan industri kreatif di Indonesia dengan menyelenggarakan kerjasama dengan berbagai pihak, baik dalam maupun luar negeri, sehingga lulusan yang dihasilkan berjiwa entrepreneurship dan mampu berkompetisi secara global.

3. Menyelenggarakan dan memasyarakatkan hasilhasil penelitian di bidang desain komunikasi visual dan teknologi multimedia melalui publikasi ilmiah, pameran, dan pengabdian kepada masyarakat (Penyusun 2018:A-65).

\section{Tujuan Program Studi}

Pada kurun waktu 2017 - 2021 Program Studi Sarjana Desain Komunikasi Visual mempunyai beberapa tujuan sebagai berikut:

1. Mendidik mahasiswa menjadi sarjana Desain Komunikasi Visual yang unggul dan memiliki kecakapan yang memadai di bidang desain komunikasi visual dan teknologi multimedia.

2. Menghasilkan lulusan yang memiliki kompetensi 
di bidang desain grafis, multimedia, advertising dan animasi.

3. Menghasilkan lulusan yang mempunyai integritas yang tinggi, beretika profesional dan berjiwa entrepreneurship.

4. Menghasilkan lulusan yang memiliki wawasan yang luas di bidang desain komunikasi visual dan teknologi multimedia sehingga mampu berkompetisi di bidang industri kreatif secara global.

5. Menghasilkan lulusan yang mampu mengembangkan profesinya sesuai dengan perkembangan teknologi informasi di bidang desain grafis, multimedia, advertising dan animasi.

6. Menghasilkan lulusan yang terampil dalam menuangkan berbagai gagasan kedalam karya, baik secara visual maupun deskriptif.

7. Mengembangkan dan memperluas kerjasama industri yang berorientasi pada peningkatan kualitas pen;elenggaraan pendidikan, penelitian dan pengabdian kepada masyarakat (Penyusun 2018:A-66).

\section{Kegiatan Mahasiswa}

1. Time Travel Community (TTC) - Komunitas Fotografi

2. Laskar Komik Udinus - Komunitas Komik

3. Dinus Goes To Animasi (DGAN) - Komunitas Animasi

\section{Karya Dan Prestasi Mahasiswa}

1. Hanif Afa Zuanmas

a. Juara 1 Lomba Video Edukasi inibudi.org Kategori Pelajar

b. Google Student Ambasador (GSA) Program

2. Lusi Noviani

Juara 1 Lomba Peksimida Tingkat Jawa Tengah Kategori Fotografi Warna

3. Sulistya Adi Nugraha

Juara 1 Lomba Peksimida Tingkat Jawa Tengah Kategori Desain Poster

4. Cristianto Harsadi (Tuna Rungu)

Finalis Lomba Fotografi "Photo Face-Off” Season

3 Perwakilan Indonesia di level Asia

\section{Program Studi Desain Komunikasi Visual sebagai Program Studi Unggulan}

Lulusan Program Studi Sarjana Desain
Komunikasi Visual mempunyai pengetahuan tentang konsep dasar, prinsip, dan teori yang berkaitan dengan bidang desain grafis, advertising, dan multimedia. Mahasiswa mempunyai konsep teoritis tentang semiotika, tinjauan desain, estetika, multimedia, konsep advertising, dan entrepreneurship, agar dapat berperan sebagai tenaga dalam desain cetak, desain editorial, desain produk dan kemasan, desain web, periklanan dan bidang terkait lainnya (Penyusun 2018: A-66). Sebagai cerminan program studi unggulan tercerminkan dalam profil lulusan yaitu Desainer Grafis, Ilustrator, Desainer Web, Fotografer, Art Director, Drafter dan Layouter, Copy Writer, Biro Iklan, Multimedia Artist (Video Editor, Digital Imaging Artist, 3D Modeller, Game Artist), Konsultan Desain, Technopreneur. Profil dan deskripsi profil dijelaskan pada table di bawah ini

Tabel 2 profil lulusan (Penyusun 2018:A-66)

\begin{tabular}{|c|c|c|}
\hline No. & Profil & Deskripsi Profil \\
\hline 1 & $\begin{array}{l}\text { Desainer } \\
\text { Grafis }\end{array}$ & $\begin{array}{l}\text { Memiliki kemampuan } \\
\text { dalam mengkaji, merancang, } \\
\text { dan mengimplementasikan } \\
\text { keilmuan bidang Desain } \\
\text { Grafis serta mengevaluasi } \\
\text { dan bertanggung jawab } \\
\text { atas hasil penilaian kerja di } \\
\text { bidang Desain Grafis. }\end{array}$ \\
\hline 2 & Ilustrator & $\begin{array}{l}\text { Memiliki pengetahuan } \\
\text { dan keterampilan dalam } \\
\text { Ilustrasi dan Gambar } \\
\text { Bentuk. }\end{array}$ \\
\hline 3 & Desainer Web & $\begin{array}{l}\text { Memiliki kemampuan } \\
\text { dalam penguasaan metode } \\
\text { dan teknik yang baik dalam } \\
\text { merancang desain web. }\end{array}$ \\
\hline 4 & Fotografer & $\begin{array}{l}\text { Memiliki kemampuan } \\
\text { dalam menguasai teknis } \\
\text { fotografi dan mampu } \\
\text { mengimplementasikannya } \\
\text { secara professional dan } \\
\text { kreatif. }\end{array}$ \\
\hline 5 & Art Director & $\begin{array}{l}\text { Memiliki kemampuan } \\
\text { dalam merancang strategi } \\
\text { konseptual dan manajemen } \\
\text { desain. }\end{array}$ \\
\hline
\end{tabular}




\begin{tabular}{|c|c|c|}
\hline No. & Profil & Deskripsi Profil \\
\hline 6 & $\begin{array}{l}\text { Drafter dan } \\
\text { Layouter }\end{array}$ & $\begin{array}{l}\text { Memiliki kemampuan } \\
\text { dalam penguasaan metode } \\
\text { dan teknik yang baik dalam } \\
\text { bidang percetakan. }\end{array}$ \\
\hline 7 & Copy Writer & $\begin{array}{l}\text { Memiliki kemampuan } \\
\text { mengidentifikasi dan } \\
\text { memecahkan masalah } \\
\text { bidang desain periklanan } \\
\text { dalam perancangan media } \\
\text { yang tepat. }\end{array}$ \\
\hline 8 & Biro Iklan & $\begin{array}{l}\text { Memiliki kemampuan } \\
\text { identifikasi dan komunikasi } \\
\text { yang baik dalam } \\
\text { perencanaan media kreatif } \\
\text { di bidang periklanan. }\end{array}$ \\
\hline 9 & $\begin{array}{l}\text { Multimedia } \\
\text { Artist (Video } \\
\text { Editor, Digital } \\
\text { Imaging Artist, } \\
3 D \text { Modeller, } \\
\text { Game Artist) }\end{array}$ & $\begin{array}{l}\text { Memiliki kemampuan } \\
\text { dalam menguasai teknis } \\
\text { Digital dan Multimedia } \\
\text { yang kuat, serta mampu } \\
\text { merancang secara } \\
\text { professional dan kreatif. }\end{array}$ \\
\hline 10 & $\begin{array}{l}\text { Konsultan } \\
\text { Desain }\end{array}$ & $\begin{array}{l}\text { Memiliki kemampuan } \\
\text { dalam menganalisis dan } \\
\text { menyelesaikan permasalahan } \\
\text { di bidang desain dengan } \\
\text { pendekatan metode yang } \\
\text { tepat. }\end{array}$ \\
\hline 11 & Technopreneur & $\begin{array}{l}\text { Memiliki kemampuan dalam } \\
\text { menumbuhkembangkan } \\
\text { jiwa kewirausahaan sejalan } \\
\text { dengan kemampuan } \\
\text { teknis keahlian dan etika } \\
\text { berwirausaha dengan penuh } \\
\text { tanggung jawab. }\end{array}$ \\
\hline
\end{tabular}

Penggambaran Program Studi Unggulan juga terpetakan dalam capaian pembelajaran dengan harapan bahwa proses pembelajaran memmenuhi standart capaian pembelajaran yang ditentukan. Terkait unsur capaian pembelajaran dan capaian pembelajaran terjabarkan pada tabel di bawah ini.
Tabel 3 capaian pembelajaran (Penyusun, 2018, p. A-67-A-70)

\begin{tabular}{|c|c|}
\hline $\begin{array}{l}\text { Unsur } \\
\text { Capaian } \\
\text { Pembelajaran }\end{array}$ & Capaian Pembelajaran \\
\hline Sikap & 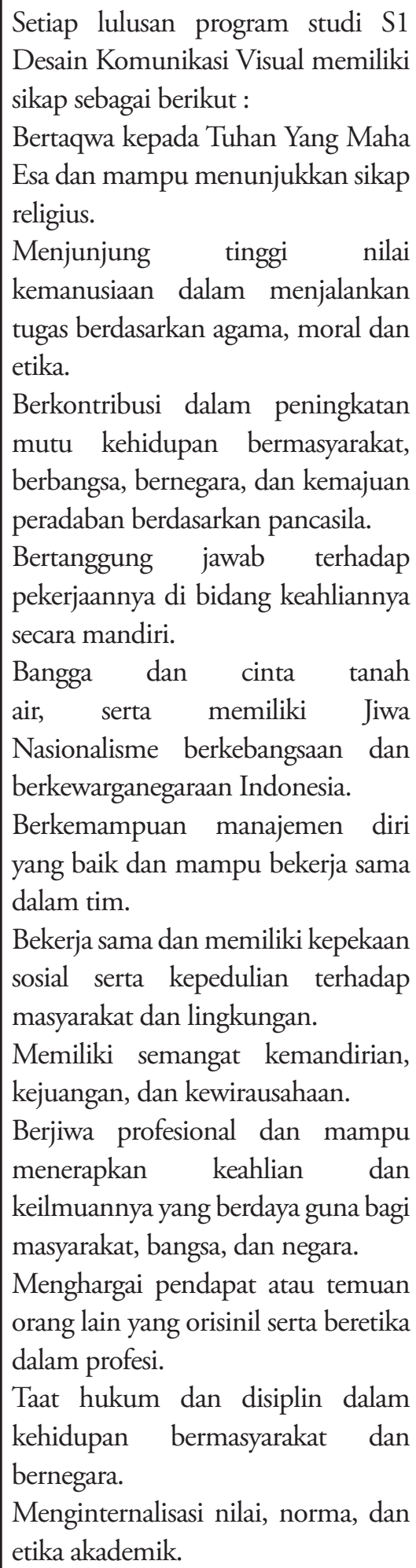 \\
\hline
\end{tabular}




\begin{tabular}{|c|c|}
\hline Pengetahuan & $\begin{array}{l}\text { Setiap lulusan program studi } \\
\text { S1 Desain Komunikasi Visual } \\
\text { memiliki pengetahuan sebagai } \\
\text { berikut: } \\
\text { Memiliki pengetahuan teoritis- } \\
\text { konseptual dan keterampilan } \\
\text { analisis dalam prinsip-prinsip, } \\
\text { metode dan perancangan desain } \\
\text { komunikasi visual, serta estetika } \\
\text { desain. } \\
\text { Menguasai teknik-teknik } \\
\text { perancangan desain komunikasi } \\
\text { visual terkait olah gambar, } \\
\text { produksi media, dan program } \\
\text { aplikatif desain komunikasi visual. } \\
\text { Berwawasan dan memiliki } \\
\text { penguasaan teknologi terkini di } \\
\text { bidang desain komunikasi visual. } \\
\text { Menguasai kaidah, prinsip dan } \\
\text { teknik komunikasi lintas fungsi, } \\
\text { level organisasi, dan budaya. } \\
\text { Menguasai prinsip dan issue terkini } \\
\text { dan perkembangan teknologi } \\
\text { terbaru secara umum. } \\
\text { Menguasai dasar manajemen dan } \\
\text { pengembangan desain komunikasi } \\
\text { visual di dalam pembuatan film } \\
\text { animasi, advertising, desain grafis, } \\
\text { maupun multimedia game. }\end{array}$ \\
\hline $\begin{array}{l}\text { Ketrampilan } \\
\text { Umum } \\
\text { Ketrampilan } \\
\text { Umum }\end{array}$ & $\begin{array}{l}\text { Setiap lulusan program studi } \\
\text { S1 Desain Komunikasi Visual } \\
\text { memiliki Ketrampilan Umum } \\
\text { sebagai berikut: } \\
\text { Mampu menerapkan pemikiran } \\
\text { logis, kritis, dan inovatif dalam } \\
\text { berkarya di bidang desain } \\
\text { komunikasi visual sesuai dengan } \\
\text { bidang keahliannya. } \\
\text { Mampu menunjukkan kinerja } \\
\text { mandiri, bermutu, dan terukur } \\
\text { dalam berkarya di bidang desain } \\
\text { komunikasi visual. } \\
\text { Mampu mengambil keputusan } \\
\text { dengan tepat dalam konteks } \\
\text { penyelesaian masalah di bidang } \\
\text { desain komunikasi visual dengan } \\
\text { memberi usulan penyelesaian } \\
\text { berdasarkan hasil analisis informasi } \\
\text { dan data yang tersedia. }\end{array}$ \\
\hline
\end{tabular}

\begin{tabular}{|c|c|}
\hline & $\begin{array}{l}\text { Mampu mengelola pembelajaran } \\
\text { secara mandiri. } \\
5 \text {. Mampu mengembangkan } \\
\text { diri dan jaringan kerjasama di } \\
\text { bidang desain komunikasi visual } \\
\text { serta berjiwa wirausaha. } \\
6 \text { Mampu mengkaji dan } \\
\text { menerapkan ilmu pengetahuan } \\
\text { dan teknologi dalam berkarya } \\
\text { sesuai dengan keahliannya } \\
\text { berdasarkan kaidah, tata cara dan } \\
\text { etika ilmiah serta menyusunnya } \\
\text { dalam sebuah hasil kerja yang } \\
\text { bermanfaat bagi masyarakat luas. }\end{array}$ \\
\hline $\begin{array}{l}\text { Ketrampilan } \\
\text { Khusus }\end{array}$ & $\begin{array}{l}\text { Setiap lulusan program studi } S 1 \\
\text { Desain Komunikasi Visual memiliki } \\
\text { Ketrampilan Khusus sebagai berikut } \\
: \text { Mampu berkomunikasi dengan } \\
\text { baik dalam pengembangan jaringan } \\
\text { kerjasama di lingkup bidang desain } \\
\text { komunikasi visual maupun di luar } \\
\text { bidang desain komunikasi visual. } \\
\text { Memiliki rasa estetis yang tinggi } \\
\text { dan memiliki wawasan budaya } \\
\text { Indonesia. } \\
\text { Mampu membuat perencanaan } \\
\text { strategis tentang sign system, } \\
\text { corporate identity, iklan layanan } \\
\text { masyarakat, maupun iklan komersial } \\
\text { melalui pencarian, identifikasi, dan } \\
\text { pemanfaatan informasi tentang } \\
\text { kebutuhan konsumen dan pasar, } \\
\text { sebagai bagian dari konsep dan } \\
\text { proses rancangan. } \\
\text { Mampu mengkomunikasikan } \\
\text { pemikiran dan hasil rancangan karya } \\
\text { desain komunikasi visual dalam } \\
\text { bentuk grafis, tulisan, dan model } \\
\text { yang komunikatif dengan teknik } \\
\text { manual maupun digital. } \\
\text { Mampu menyajikan beberapa } \\
\text { alternatif solusi rancangan karya } \\
\text { desain komunikasi visual dan } \\
\text { membuat keputusan pilihan } \\
\text { berdasarkan pertimbangan keilmuan } \\
\text { desain komunikasi visual. }\end{array}$ \\
\hline
\end{tabular}




\begin{tabular}{|l|l|}
\hline & $\begin{array}{l}\text { Memiliki kemampuan dalam } \\
\text { perencanaan, implementasi, dan } \\
\text { pengembangan desain komunikasi }\end{array}$ \\
visual dalam dunia kerja dan bisnis. \\
Mampu mengimplementasikan \\
prinsip-prinsip perancangan desain \\
komunikasi visual dalam pembuatan \\
film animasi, advertising, desain \\
grafis, maupun multimedia game.
\end{tabular}

Berdasarkan profil lulusan dan capaian pembelajaran yang sudah terpetakan untuk mencapai kualitas dan kuantitas sumberdaya manusia dengan kompetensi bidang ilmu desain komunikasi visual sehingga tercapainya kemampuan khusus bagi mahasiswa. Kemampuan khusus yang mengarahkan pada pembentukan karakter mahasiswa desain komunikasi visual. Adapun Kemampuan Khusus Mahasiswa Desain Komunikasi Visual di antaranya:

1. Ilustrasi, Animasi \& Audio Visual

2. Komputer Grafis, Multimedia dan Desain Web

3. Fotografi, Periklanan / Advertising \& Teknologi Cetak

4. Manajemen Desain \& Komunikasi Bisnis

5. Desain Logo \& Media Komunikasi Visual

\section{Media Digital dalam Penanaman Program Studi Uggulan}

Kata "media" berasal dari bahasa Latin "medium" yang berarti "perantara" atau "pengantar". Lebih lanjut, media merupakan sarana penyalur pesan atau informasi belajar yang hendak disampaikan oleh sumber pesan kepada sasaran atau penerima pesan tersebut. Penggunaan media pengajaran dapat membantu pencapaian keberhasilan belajar. media adalah berkaitan dengan perantara yang berfungsi menyalurkan pesan dan informasi dari sumber yang akan diterima oleh si penerima pesan yang terjadi dalam proses pembelajaran (Mahnun, 2012, p. 27). Seperti semua media, media digital mewakili dunia, bukan hanya mencerminkannya (Buckingham, 2007a, p. 48). European Commission menyebutkan "Media literacy is generally defined as the ability to access the media, to understand and to critically evaluate different aspects of the media and media content and to create communications in a variety of contexts" (Koltay, 2011, p. 213). (Literasi media secara umum didefinisikan sebagai kemampuan untuk mengakses media, untuk memahami dan mengevaluasi secara kritis berbagai aspek media dan konten media dan untuk menciptakan komunikasi dalam berbagai konteks).

Rudy Bretz mengklasifikasi media menurut ciri utama media menjadi tiga unsur, yaitu suara, visual, dan gerak. Selanjutnya, klasifikasi tersebut dikembangkan menjadi tujuh kelompok, yaitu: a). Media audio-visual-gerak; merupakan media paling lengkap karena menggunakan kemampuan audio-visual dan gerak, b). Media audio- visualdiam; memiliki kemampuan audio-visual tanpa kemampuan gerak, c). Media audio-semi-gerak; menampilkan suara dengan disertai gerakan titik secara linear dan tidak dapat menampilkan gambar nyata secara utuh, d). Media visual-gerak; memiliki kemampuan visual dan gerakan tanpa disertai suara, e). Media visual-diam; memiliki kemampuan menyampaikan informasi secara visual tetapi tidak menampilkan suara maupun gerak, f). Media audio; media yang hanya memanipulasi kemampuan mengeluarkan suara saja, g). Media cetak; media yang hanya mampu menampilkan informasi berupa huruf-huruf dan simbol-simbol verbal tertentu saja (Mahnun, 2012, p. 30).

Literasi juga melibatkan pemahaman siapa yang berkomunikasi dengan siapa, dan mengapa. Dalam konteks media digital, kaum muda perlu menyadari semakin pentingnya pengaruh komersial - terutama karena ini sering tidak terlihat oleh pengguna. Buckingham (2007b, p. 44) mengungkapkan, bahwa "media literacy is the ability to access, understand and create communications in a variety of contexts" (literasi media adalah kemampuan untuk mengakses, memahami, dan menciptakan komunikasi dalam berbagai konteks).

Coleman (2010, p. 495) mengungkapkan, bahwa "digital media in similarly prosaic terms means uncovering the lived experiences of dig-ital media; discussing the conditions in which they are made, altered, and deployed (finance, religion, news); attending to particular genres of communication (blogs, spam, videosharing sites); and finally placing attention on the material and ideological functions produced and sustained by digital technologies (mengungkap pengalaman hidup dari media digital; membahas kondisi di mana mereka dibuat, diubah, dan digunakan (keuangan, agama, berita); menghadiri genre komunikasi tertentu (blog, spam, situs berbagi video); dan akhirnya menaruh perhatian pada fungsi material 
dan ideologis yang dihasilkan dan dipertahankan oleh teknologi digital).

\section{Media web}

Desain web DKV Udinus menyajikan segala kegiatan mahasiswa. Adapun, galeri DKV Udinus lebih menekankan pada karya-karya yang pernah disajikan dalam ajang pameran tugas akhir, pameran angkatan, dan berbagai karya yang diajang pameran skala lokal maupun internasional. Pada konsep galeri DKV Udinus sudah dipetakan sesuai peminatan sebagai contoh karya-karya advertising, animasi, dan desain grafis.

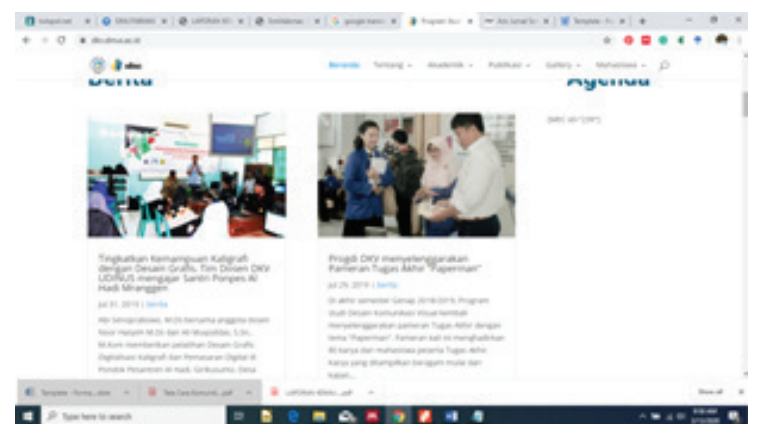

Gambar 1. Tampilan media web DKV Udinus (Screenshot Agus Setiawan, 2020)

\section{Media Youtube}

Salah satu bentuk konten positif adalah konten yang memiliki tema atau topik pendidikan. Terkait konten pendidikan di media sosial YouTube sebagai salah satu media yang sangat digemari oleh anak muda saat ini. Popularitas YouTube salah satunya adalah terkait dengan fakta bahwa konten di media digital dalam bentuk video sedang menjamur (Nielsen, 2016; Vollmer, 2017; We Are Social, 2017),

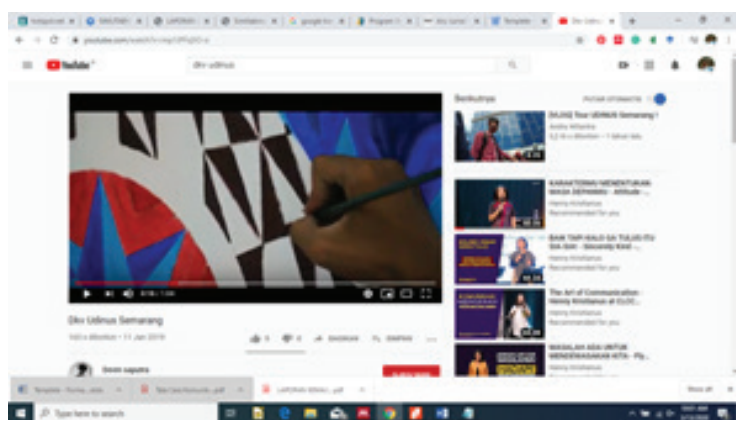

Gambar 1. Tampilan video pada kanal youtube (Screenshot Agus Setiawan, 2020)

\section{Media Instagram}

Jejaring media social tak luput dari perhatian mengingat gaya trend mahasiswa sering mengabadikan momennya pada platform Instagram. Salah satu contoh kegiatan yang bertajik antara masa dalam rangka ulang tahun DKV Udinus ke 10 tahun di isi dengan launcing buku rupa-rupa komunikasi visual kekinian hasil buah pikiran dari bapak ibu dosen DKV Udinus.

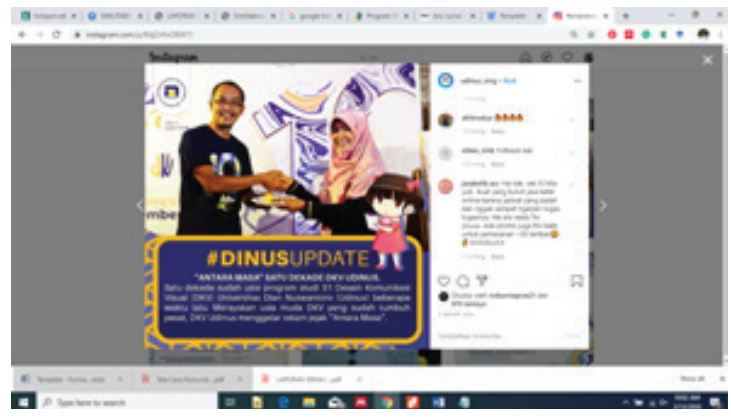

Gambar 3. Tampilan Instagram DKV Udinus (Screenshot Agus Setiawan, 2020)

\section{Media Facebook}

Media digital facebook digunakan sebagai media informasi Kerja Praktek, Kuliah Kerja Industri dan Tugas Akhir. Media facebook digunakan koordinator KP KKI dan coordinator TA untuk menginformasikan semua kegiatan akademik. Media ini cukup efektif guna membangun ruang dialog bagi mahasiswa dengan dosen.

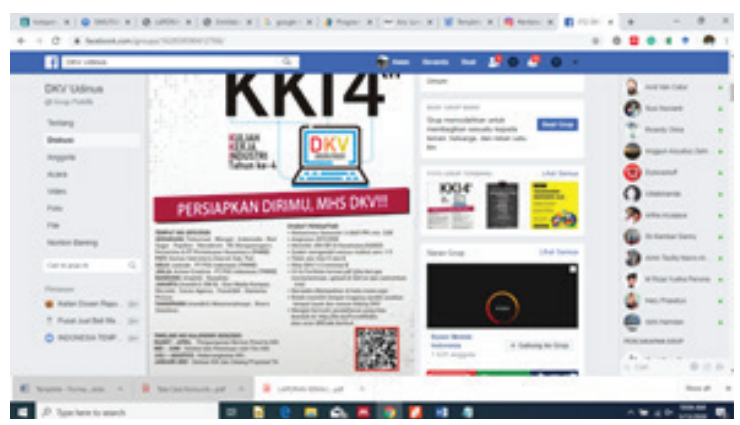

Gambar 4. Tampilan media facebook yang menampilkan informasi bagi mahasiswa (Screenshot Agus Setiawan, 2020)

\section{Simpulan}

Keberadaan media digital dapat digunakan sebagai media pengenalan, pembelajaran kepada mahasiswa dan calon mahasiswa baru serta masyarakat, bahwa pilihannya sudah tepat dan berada pada tempat yang tepat pula. pencapaian media digital yaitu tindakan untuk mengakses, menidentifikasi, menganalisis dan membangun 
pengetahuan baru melalui media digital berupa video profil desain komunikasi visual. Melalui video profil tersebut upaya pembentukan wajah program studi unggulan mampu memberikan ruang interaksi kearah pemahaman dan pemantapan pilihan. Solusi yang dicapai adalah tercapainya media digital sebagai penanaman karater tentang wajah sebuah program studi yang unggul sehingga secara konsep literasi media memicu pengetahuan baru tentang sebuah progam studi yang unggul. Di sisi lain, pencapaian media digital menjadi langkah lanjutan dari penelitian yang pernah dilakukan terkait pengembangan institusi pada program studi desain komunikasi visual Udinus yaitu penciptaak web DKV Udinus sebagai bentuk wadah literasi visual dan tata kelola pameran yang mengarah pada konsep pameran digital. Untuk melengkapi dari dari keberadaan program studi dalam katagori A maka perlu terciptanya media digital dalam menjawab tantangan sebagai program studi unggulan

\section{Ucapan Terima Kasih}

Ucapan terima kasih penulis sampaikan kepada LPPM Universitas Dian Nuswantoro atas fasilitas dan hibah penelitian internal.

\section{Daftar Pustaka}

Anggraini, S. (2016). Budaya Literasi Dalam Komunikasi. WACANA, XV(3), 181-279.

Buckingham, D. (2007a). Digital Media Literacies: rethinking media education in the age of the Internet. Research in Comparative and International Education, 2(1), 43-55.

Buckingham, D. (2007b). Digital Media Literacies: Rethinking Media Education in the Age of the Internet. Research in Comparative and International Education, 2(1), 43-55. https://doi.org/10.2304/rcie.2007.2.1.43

Coleman, E. G. (2010). Ethnographic approaches to digital media. The Annual Review of Anthropology, 39(1), 487-505. I

Creswell, J.W. (1998). Qualitative Inquiry and Research Design. California: Sage Publication, inc.

Creswell, John W. (2016). Research Design: Pendekatan Metode Kualitatif, Kuantitatif, dan Campuran. (A. dan R. K. P. Fawaid, Trans.) (keempat). Yogyakarta: Pustaka Pelajar.
Koltay, T. (2011). The media and the literacies: media literacy, information literacy, digital. Media Culture Society, 33(2), $211-221$. https://doi.org/10.1177/0163443710393382

Mahnun, N. (2012). MEDIA PEMBELAJARAN (Kajian terhadap Langkah-langkah Pemilihan Media dan Implementasinya dalam Pembelajaran). Jurnal Pemikiran Islam, 37(1), 27-34.

Nugraini, S. H. (2019). Program Studi DKV UDINUS. Retrieved March 13, 2020, from https://dkv.dinus.ac.id/

Penyusun, T. (2018). Panduan Buku Akademik 2017/2018. Semarang: Universitas Dian Nuswantoro. 